\title{
Donovanosis in a child victim of sexual abuse: response to doxycycline treatment*
}

\author{
Bárbara Machado Magalhães ${ }^{1}$, John Verrinder Veasey ${ }^{1}$, Silvia Assumpção Soutto Mayor ${ }^{1}$, \\ Rute Facchini Lellis ${ }^{2}$
}

DOI: http:/ / dx.doi.org/10.1590/abd1806-4841.20187948

\begin{abstract}
Donovanosis is a chronic infectious disease caused by the Gram-negative bacteria Klebsiella granulomatis, which mainly affects the skin and mucous membranes of the genital, perigenital, and inguinal regions. Also known as venereal granuloma or granuloma inguinale, it is endemic in tropical and subtropical regions of the globe and often associated with sexual transmission. We report the case of an 11-year-old female victim of chronic sexual abuse, who was diagnosed with donovanosis and presented a good therapeutic response to doxycycline.
\end{abstract}

Keywords: Child; Child abuse, sexual; Dermatology; Doxycycline; Granuloma inguinale; Sex offenses; Sexually transmitted diseases; Vulvar diseases

Donovanosis is a sexually transmitted infection (STI) caused by Klebsiella granulomatis and often transmitted by sexual contact. It is a secular disease endemic in tropical and subtropical countries and affects both men and women, especially between 20 and 40 years of age. ${ }^{1}$ Low socioeconomic status, poor hygiene, and sexual promiscuity are the main risk factors. ${ }^{2}$
We report a case of an 11-year-old female, victim of chronic sexual abuse, who presented with an asymptomatic vulvar lesion with one month of progressive growth. The examination revealed localized dermatosis in the internal region of the labia majora, characterized by two symmetrical and erythematous ulcers with well-defined borders (Figure 1). A biopsy and a direct cytological examination were performed, but only the anatomopathological examination
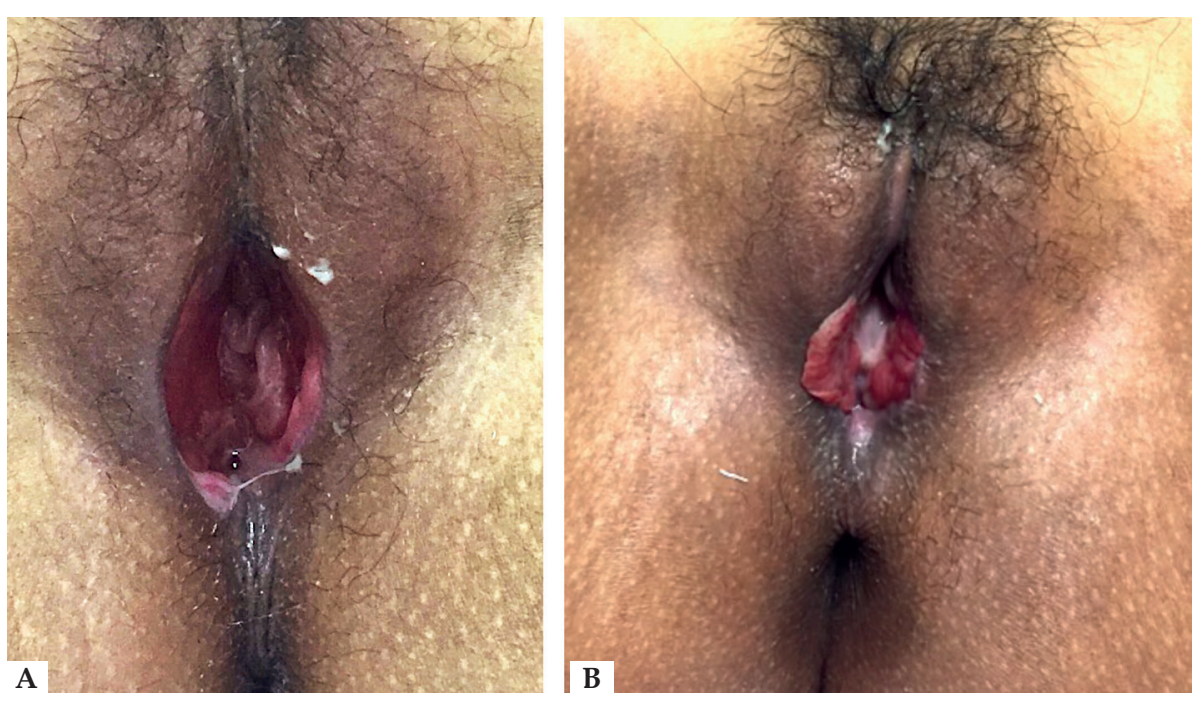

Figure 1: Clinical aspect of the lesion, characterized by well-defined ulcers and erythematous and granular base located bilaterally on the inner side of the labia majora. A - pre-treatment B 3-week response with doxycycline

\section{Received 08 December 2017}

Accepted 06 March 2018

* Work conducted at the Dermatology Clinic, Santa Casa de São Paulo, São Paulo (SP), Brazil.

Financial Support: None.

Conflict of Interest: None.

Dermatology Clinic, Santa Casa de São Paulo, São Paulo (SP), Brazil.

Laboratory of Pathology, Santa Casa de São Paulo, São Paulo (SP), Brazil.

Mailing Address:

John Verrinder Veasey

E-mail: johnveasey@uol.com.br 

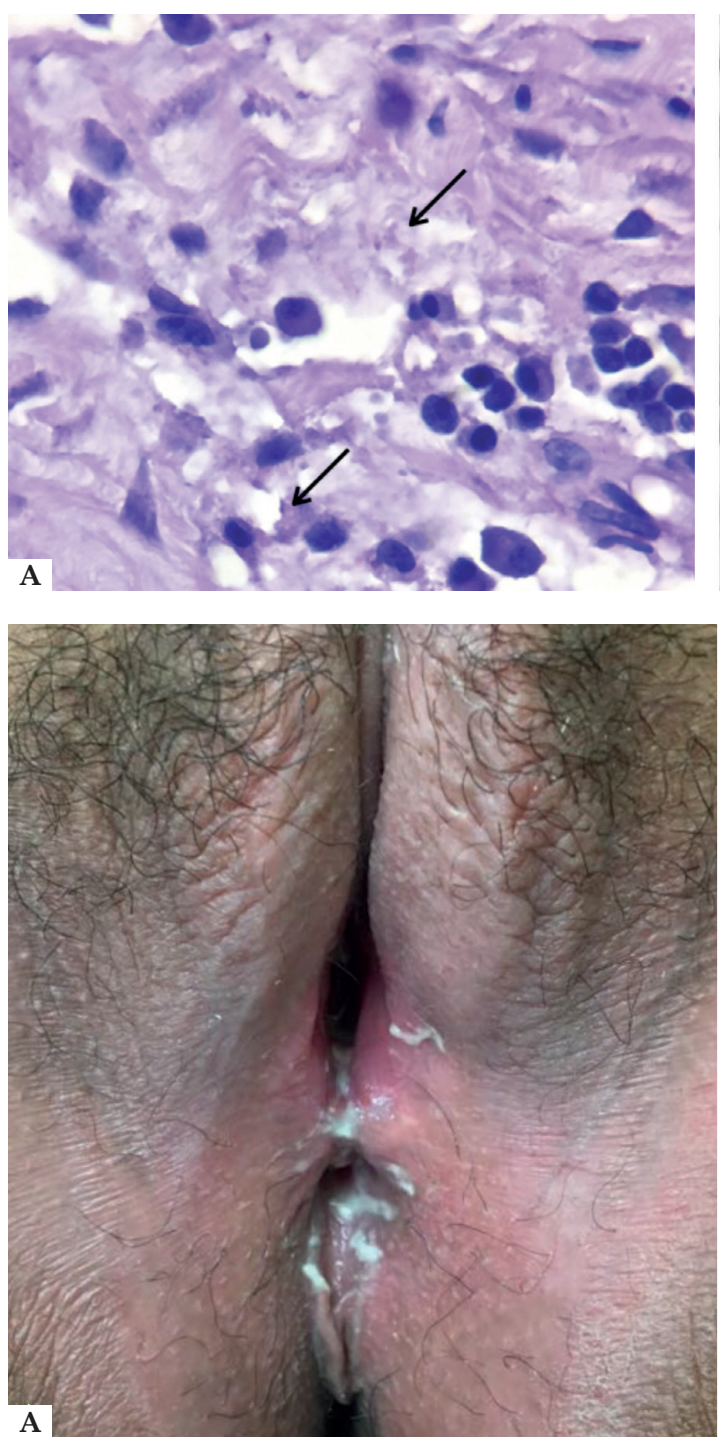
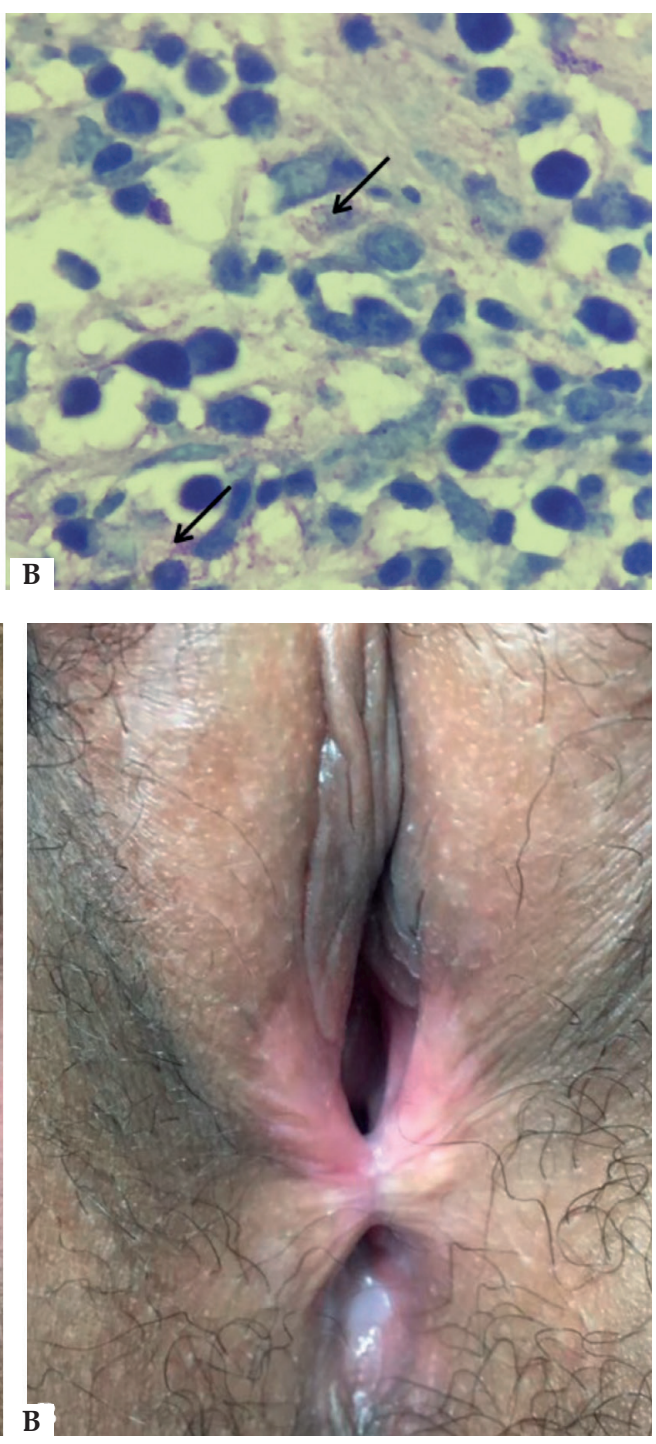

Figure 2: Histopathological examination: A - mixed inflammatory infiltrate and macrophages with ample cytoplasm filled with bacilli (arrows) (Hematoxylin \& eosin $x 400$ ) B - Bacilli containg macrophages (arrows) (Giemsa $\mathrm{x} 400$ )

Figure 3: A - Healing process at the end of 20 weeks of treatment B - sustained healing at 3 weeks of follow-up revealed the Donovan corpuscles (DC) (Figure 2). Serologies for other STIs were requested; all were non-reactive. The patient was treated with doxycycline for 20 weeks, attaining complete remission of the lesions (Figure 3). As a victim of sexual abuse, she was also evaluated by pediatricians, psychologists, and social workers.

According to the World Health Organization (WHO), child abuse is defined as abuse and neglect of all children under the age of 18, including physical, psychological, and sexual abuse as well as neglect and commercial exploitation. Just as there is controversy about the association between anogenital condylomata in children and child sexual abuse, cases of donovanosis in children are frequently associated with infected adults, but are not necessarily due to sexual contact. ${ }^{2-4}$ In the case presented here, the patient had a known history of abuse before the diagnosis of the disease, and there was no doubt of the contagion.

Donovanosis presents an incubation period ranging from 1 to 360 days, with an average of 50 days. Clinical presentation begins with a painless papule or nodule that evolves slowly, ulcerating into a softened and erythematous lesion with well-defined, hardened and elevated irregular borders ${ }^{1}$. Both the clinical presentation and chronology of this case are compatible with the classic description.

Diagnosis is based on the clinical characteristics of the lesions and on the identification of the bacteria ${ }^{5}$. K. granulomatis is an intracellular organism that, when phagocyted by large histiocytes, forms DC. ${ }^{6}$ These corpuscles can be identified using Wright, Giemsa or Leishman stains in the direct examination of a lesion smear and in the histopathological examination. In the presented case, the DC was evident in the histopathological examination, but not in the direct examination of the smear.

Doxycycline (100mg bid) is the first line of treatment according to Brazil's Ministry of $\mathrm{Health}^{7}$ and the $\mathrm{WHO}^{8}$, and the second option according to the Centers for Disease Control and Prevention. ${ }^{9}$ It can be prescribed for children over 8 years old, and the treatment should be continued until clinical remission, which can take between 2 weeks and 3 months. Follow up should be kept for at least 18 months. In our case, the patient received 20 weeks of treatment, with sustained healing at the clinical follow-up at 23 weeks.

Donovanosis is an STI rarely reported in scientific journals. The recognition of the clinical lesion and laboratory confirmation of the diagnosis are crucial, given the prolonged treatment of this disease. $\square$ 


\section{REFERENCES}

1. Velho PE, Souza EM, Belda Junior W.. Donovanosis. Braz J Infect Dis. 2008:12:521-5

2. Costa MC, Bornhausen Demarch E, Azulay DR, Périssé AR, Dias MF, Nery JA. Sexually transmitted diseases during pregnancy: a synthesis of particularities. An Bras Dermatol. 2010 Nov-Dec;85(6):767-82.

3. Costa-Silva M, Fernandes I, Rodrigues AG, Lisboa C. Anogenital warts in pediatric population. An Bras Dermatol. 2017;92:675-681.

4. Veasey JV, Dall'Antonia M, Miguel BAF, Mayor SAS, Campaner AB, Manzione TS. Anogenital condylomas in children: descriptive analysis of 20 cases. Surg Cosmet Dermatol 2017;9:127-9.
5. Bezerra SM, Jardim MM, Silva VB. Granuloma inguinale (Donovanosis). An Bras Dermatol. 2011;86:585-6.

6. $\quad 0$ 'Farrell N. Donovanosis. Sex Transm Infect. 2002:78:452-7.

7. Brasil. Ministério da Saúde. Secretaria de Vigilância em Saúde. Departamento de DST. Aids e Hepatites Virais. Protocolo Clínico e Diretrizes Terapêuticas para Atenção Integral às pessoas com Infecções Sexualmente Transmissíveis. Brasília: Ministério da Saúde; 2015. p. 70.

8. World Health Association. Guidelines for the management of sexually transmitted infections. Geneva: World Health Association; 2003. p.47-8

9. Workowski KA, Bolan GA. Granuloma Inguinale (Donovanosis) in Sexually Transmitted Diseases Treatment Guidelines. MMWR 2015;64:1-133.

\section{AUTHORS CONTRIBUTION}

Bárbara Machado Magalhães

iD ORCID 0000-0002-4605-9150

Elaboration and writing of the manuscript; Obtaining, analyzing and interpreting the data; Intellectual participation in propaedeutic and/or therapeutic conduct of cases studied

John Verrinder Veasey

(iD) ORCID 0000-0002-4256-5734

Approval of the final version of the manuscript; Conception and planning if the study; Elaboration and writing of the manuscript; Effective participation in research orientation Intellectual participation in propaedeutic and/or therapeutic conduct of cases studied; Critical review of the literature; Critical review of the manuscript

\section{Silvia Assumpção Soutto Mayor \\ ORCID 0000-0001-9335-2758}

Intellectual participation in propaedeutic and/or therapeutic conduct of cases studied

Rute Facchini Lellis

ORCID

0000-0001-7690-0513

Obtaining, analyzing and interpreting the data

How to cite this article: Magalhaes BM, Veasey JV, Mayor SAS, Lellis RF. Donovanosis in a child victim of sexual abuse: response to doxycycline treatment. An Bras Dermatol. 2018;93(4):592-4. 